\title{
Hope in Hard Times
}

\author{
Mayri Sagady Leslie, MSN, CNM
}

\begin{abstract}
In the face of challenging times, advocates for women and their families in maternal-child health care continue to promote evidence-based and mother-/baby-friendly care. What qualities allow childbirth educators, doulas, nurses, and perinatal care providers to keep going even when the health-care practices around them often do not match their values? This editorial explores the impact of recent trends in which increasing utilization of elective technology in maternity care may affect the individual commitment of childbirth advocates. Borrowing from research on successful advocates in other fields, the author speculates on both why and how childbirth advocates sustain commitment and how "we will prevail."
\end{abstract}

Journal of Perinatal Education, 17(1), 7-10, doi: 10.1624/105812408X267907

Keywords: cesarean, cesarean prevention, induction, labor, vaginal birth after cesarean, advocate, childbirth educator, doula, nurses, midwives, doctors, care providers, commitment, collaboration, vocation, hope, difficult times

Conflict is the midwife of consciousness.

(Freire \& Horton, 1990, p. 176)

Silly me. I spent several years developing the concept of the "preventable cesarean," determined to help avoid cesareans that, while necessary at the time they were performed, could have been prevented earlier on in the labor by abstaining from some interventions or by initiating others. This effort began with my master's degree work at Case Western Reserve University, followed by years of writing and talking about cesarean prevention and, then, creating consulting programs to transform nursing culture in hospitals that were actually interested in lowering their cesarean rates. Ah, those were the days.

As we all know, times have changed. Although the evidence still emphatically supports avoiding cesareans for which no true medical indication exists, this fact alone does not seem to be sufficient for reducing worldwide cesarean rates. For example, in the United States, it was not sufficient to have the National Institutes of Health's 2006 conference, "Cesarean Delivery on Maternal Request," make a strong recommendation against elective operative births. In fact, the National Center for Health Statistics recently released the preliminary birth data for 2006, revealing another increase in the U.S. cesarean rate to $31.1 \%$, which marks a $50 \%$ increase over the last 10 years in the use of surgery to have babies (Hamilton, Martin, \&Ventura, 2007). The other major contribution to the acceleration of the climbing cesarean rate is that we seem to be witnessing the near extinction of vaginal births after cesarean (VBACs) as an option for women in the United States. In 1996, the VBAC rate was $28.3 \%$ while, in 2004 , it dropped to the low of $9.2 \%$, representing the second successive year with a $16 \%$ decline (Martin et al., 2007; Menacker \& Curtin, 2001).

To make matters worse, it is not just about cesareans, is it? The brewing stew includes induction for all manner of nonmedical, prophylactic reasons. 
Babies might be too big or too late. Every woman with a broken bag of waters should now be induced, despite no change in the evidence to support such a change in practice. The rub is, as they say, we don't really even know how many inductions are being done. Using birth certificate data in the United States, the National Center for Health Statistics reported $22.3 \%$ for 2005, an induction rate that has doubled since 1990 (Martin et al., 2007). However, in Listening to Mothers II, the only U.S. survey of what mothers themselves actually experience, the women reported a provider induction rate of $34 \%$ (Declercq, Sakala, Corry, \& Applebaum, 2006). This statistic is likely to be closer to the truth, if not even a little conservative. Multiple studies comparing the accuracy of birth certificate data to actual hospital records and/or discharge data have consistently found induction rates to be underreported (Lydon-Rochelle et al., 2005; Northam \& Knapp, 2006; Yasmeen, Romano, Schembri, Keyzer, \& Gilbert, 2006).

Between the two-cesareans and induction-we could just recycle all the brochures on our shelves about "how to know when your labor has started" and ask Al Gore what to do with them. After all, he just received the 2007 Nobel Peace Prize for taking a stand on global warming, which was about as popular an issue among the scientific community a few years back as normal birth is in our maternity care system today.

Seriously, if you haven't been just a little depressed in the last 24-48 months about the direction of maternity care, you would be unusual, to say the least. (Or if you weren't before you started this editorial, you probably are by now.) As educators, doulas, advocates, nurses, midwives, physicians, and providers of normal birth and mother-/babyfriendly care, these are very tough times. Here is the interesting thing, though: You are still here. Why?

\section{EXTRAORDINARY ACTIVISTS AND BEING CALLED}

I recently read a study conducted by Kovan and Dirkx (2003) on exemplary, experienced, environmental activists. What caught my eye were the qual-

Vocation at its deepest level is "something I can't not do, for reasons I'm unable to explain to anyone else and don't fully understand myself but that are nonetheless compelling." ities the researchers found in the extraordinary human beings included in their study and, especially, the forces that sustained them. The authors describe three key components that exemplified the individuals in their study: a sense of vocation, passion, and commitment.

Using the term vocation to describe one's work brings to mind the sense of being called to something. Indeed, the word vocation comes from the Latin vocare, meaning "to call" (MSN Encarta ${ }^{\circledR}$ World English Dictionary, 2007). According to Palmer (2000), vocation at its deepest level is "something I can't not do, for reasons I'm unable to explain to anyone else and don't fully understand myself but that are nonetheless compelling" (p. 25). To me, Palmer's use of the word vocation describes the pursuit of just about every dedicated childbirth advocate and professional I know. In addition, this is a field that requires passion and commitment. Many individuals who seek and/or remain in the service of mothers, babies, and families have a fire within them and the commitment to see that passion through.

Likewise, as described in Kovan and Dirkx's (2003) qualitative study, the following three themes described below were consistently evident in the life of each successful activist and rang true for me as being qualities also found in those of us who are called to this work.

\section{Learning to Listen to What Is Not Known}

The first theme is described as "Learning to Listen to What Is Not Known." One of the largest gaps between the medical, technocratic view of childbirth and a more holistic, mother-centered perspective is a tolerance for the unknown, for the immeasurable, for the value and power of the intuitive and implicit aspects of what we see, know, and do. I believe such tolerance is at the core of this model when it is working at its best. Whether you call it "mother-friendly care," "normal birth practices," the "midwifery model of care," or something else, it is the synthesis of many care practices that, when added together, are far more than the sum of their parts. This model of care is glued together by a compilation of components, and it can disappear when you try to break it into pieces and study each element separately from the whole. I propose that one way to describe that glue is to describe maternity care providers' and advocates' ability to listen to what is not known, to hear it, and then provide it. Doing so requires a tolerance for ambiguity and uncertainty and for experimentation 
and failure, experiences we have all known and will continue to face. The ability to continue working toward our commitment in the face of such challenges is the true measure of success in our work. However, it won't measure our ability to reach the finish line. As most of us have noticed, the finish line keeps moving anyway, and it always will. These unique and abstract aspects of our model and our elusive competencies are among the reasons that attempts at traditional research often fail to reveal the effectiveness of individual care practices when they are isolated from the model.

\section{Connecting With and Working From the Heart}

The second theme from Kovan and Dirkx's (2003) study is "Connecting With and Working from the Heart." Okay, I thought while reading this one-we have this one down. Except that the real challenge is keeping connected and not losing heart. No one among us was drawn to this work by anything if not our hearts. The struggle here is that many of us find ourselves working within a dominant paradigm that holds many values contradictory to our own, inside of which issues that are of paramount importance to us are not perceived as issues at all. For instance, what is the big deal with the fact that we are heading toward a time when most women will have their babies cut out or pulled out of their bodies? Being able to work from the heart in our particular world requires sustaining a reality of what we believe, despite being inside an often less than supportive environment. This being the case, the importance of staying connected to other, likeminded colleagues is paramount.

In Kovan and Dirkx's (2003) study, it was interesting to read the activists' point that, sometimes, the only way to keep this quality in place is to take a break and take care of yourself. For them, this included changing jobs, enjoying a vacation, or even taking a complete hiatus from the field. I know that I often drive myself as if nothing will continue if I don't keep going. Although it is true that we seem to be running a marathon at times (the one with the continually moving finish line), we are not in it alone. It is not our brilliance or our physical endurance that will sustain us-it is our heart and that which called us in the first place-and it is that heart that we need to attend to.

\section{Learning to Live Through Difficult Times}

The third and last theme from Kovan and Dirkx's (2003) study is this: "Learning to Live Through Dif-
It is not our brilliance or our physical endurance that will sustain

us - it is our heart and that which called us in the first

place-and it is that heart that we need to attend to.

ficult Times." Well, here we are, aren't we? I once got into politically incorrect trouble for likening what is happening in the childbirth movement to the Battle of Gettysburg in the American Civil War. (War analogies are not popular these days.) Before the days of aircraft and satellites, the only way to know what was going on in other parts of the battle was to hold the high ground. Hence, one of the greatest issues of contention at Gettysburg was to hold Little Round Top-the high ground. Otherwise, forces might put all their resources into one battle, while not knowing that, strategically, the bigger battle is around the other side and requires greater support. Hence, win the little battle, lose the war.

Back when I was working with the nurses on preventing cesareans, I had little idea of what was brewing on other fronts. I focused on cesarean prevention by working with nursing cultures (not a bad approach). Meanwhile, vaginal birth after cesarean and breech birth were coming under fire, and elective cesareans were brewing just around the corner. I think many of us had a limited vision of what was coming, but few could comprehend or imagine just how difficult these difficult times would get.

Will we learn to live through such difficult times? Is it worth it? The answer to such questions is a resounding yes! How do I know? First, we would not be in this world of birthing women and families if it was not our vocation, passion, and commitment. We have been called. It is a call that is loud and clear and is rarely silent. (In fact, it seems to have unlimited minutes.) I also have the audacity to think, and say out loud, that I believe we will get through these difficult times because, in the end, what is right, ethical, and evidence-based will and must prevail. I know that sounds naïve and unrealistic, but at the core of the issues we support, we have our own "inconvenient truths" that will stand the test of time. For my part, I don't really think it was silly of me to try to change things back then. In fact, I have never stopped. This is how we all get through the difficult times-by taking one step at a time, by having hope, and by working together. 
Together, we must see outside the lines and create new

solutions to do what we have always been called to do.

M

To learn more about The Birth Survey, log on to www.thebirthsurvey.com

\section{HOPE AND COLLABORATION}

Here is where I see hope. I see an emerging generation of young women who are thinking for themselves and seeing that the current maternity system has many serious issues, and they have a passion to make it better. I see new waves of evidence being generated and enough good people working with that evidence and, in turn, trying new solutions in the field to reverse the trends toward nonindicated inductions and cesareans. Payors of healthcare costs are starting to put their foot down and say, "This is enough!” Finally, a strong grassroots movement is coming alive and growing again. For example, The Birth Survey, an Internet-based transparency project, is harnessing the power of mothers' voices about their birth experiences so that mothers-to-be can learn about their options for providers and places of birth to make more informed choices. The project also gives health-care professionals and institutions access to invaluable feedback on their services.

The final part of my message is simple. It is time for all of us to take the "high ground" on the battlefield and see the bigger picture, together. Coalitions, collaborations, partnerships, and parallel strategies are called for. We need each other and, with each other, we will prevail in these difficult times. Together, we must see outside the lines and create new solutions to do what we have always been called to do. The stakes are too high to do otherwise.

\section{REFERENCES}

Declercq, E. R., Sakala, C., Corry, M. P., \& Applebaum, S. (2006). Listening to mothers II: Report of the second national U.S. survey of women's childbearing experiences. New York: Childbirth Connection.

Freire, P., \& Horton, M. (1990). We make the road by walking. Philadelphia: Temple Press.

Hamilton, B. E., Martin, J. A., \& Ventura, S. J. (2007). Births: Preliminary data for 2006. National Vital Statis- tics Reports, 56(7). Hyattsville, MD: National Center for Health Statistics. Retrieved December 8, 2007, from http:// www.cdc.gov/nchs/data/nvsr/nvsr56/nvsr56_07.pdf

Kovan, J. T., \& Dirkx, J. M. (2003). "Being called awake": The role of transformative learning in the lives of environmental activists. Adult Education Quarterly, 53(2), 99-118.

Lydon-Rochelle, M. T., Holt, V. L., Nelson, J. C., Cardenas, V., Gardella, C., Easterling, T. R., et al. (2005). Accuracy of reporting maternal in-hospital diagnosis and intrapartum procedures in Washington State linked birth records. Paediatric and Perinatal Epidemiology, 19(6), 460-471.

Martin, J. A., Hamilton, B. E., Sutton, P. D., Ventura, S. J., Menacker, F., Kirmeyer, S., et al. (2007). Births: Final data for 2005. National Vital Statistics Reports, 56(6). Hyattsville, MD: National Center for Health Statistics. Retrieved December 11, 2007, from http://www.cdc. gov/nchs/data/nvsr/nvsr56/nvsr56_06.pdf

Menacker, F., \& Curtin, S. C. (2001). Trends in cesarean birth and vaginal birth after previous cesarean, 1991-99. National Vital Statistics Reports, 49(13). Hyattsville, MD: National Center for Health Statistics. Retrieved January 12, 2008, from http://www.cdc. gov/nchs/data/nvsr/nvsr49/nvsr49_13.pdf

MSN Encarta ${ }^{\circledR}$ World English Dictionary. (2007). Vocation. Retrieved December 9, 2007, from http://encarta. msn.com/dictionary_/vocation.html

National Institutes of Health [NIH]. (2006, March 2729). NIH state-of-the-science conference statement on cesarean delivery on maternal request. NIH Consensus and State-of-the-Science Statements, 23(1), 1-29.

Northam, S., \& Knapp, T. R. (2006). The reliability and validity of birth certificates. Journal of Obstetric, Gynecologic, and Neonatal Nursing, 35(1), 3-12.

Palmer, P. J. (2000). Let your life speak: Listening for the voice of vocation. San Francisco: Jossey-Bass.

Yasmeen, S., Romano, P. S., Schembri, M. E., Keyzer, J. M., \& Gilbert, W. M. (2006). Accuracy of obstetric diagnoses and procedures in hospital discharge data. American Journal of Obstetrics \& Gynecology, 194(4), 992-1001.

MAYRI SAGADY LESLIE is a faculty member for the Graduate Nurse-Midwifery Program at the School of Nursing and Health Studies at Georgetown University in Washington, DC. She is also the Chair of the Coalition for Improving Maternity Services and serves on the board of the International MotherBaby Childbirth Organization. 